\title{
Determinação da Concentração Inibitória Mínima do Clotrimazol e da Terbinafina sobre isolados de Candida albicans oriundas da mucosa bucal de pacientes HIV positivos e HIV negativos
}

\author{
André Luis Ribeiro CLAUDINO ${ }^{1}$ \\ Cristiane Sbruzi GRANJA ${ }^{2}$ \\ Adriene Ribeiro LIMA ${ }^{3}$ \\ Claudete Rodrigues PAULA ${ }^{4}$ \\ Natanael Atilas ALEVA ${ }^{5}$ \\ Renata Beatriz SILVA ${ }^{6}$ \\ Jorge Kleber CHAVASCO ${ }^{7}$
}

\footnotetext{
${ }^{1,2}$ e 3 Biólogos pela UNIFAL-MG (Universidade Federal de Alfenas).

${ }^{4}$ Farmacêutica e Professora Titular da USP (Universidade de São Paulo).

${ }^{5}$ Cirurgião Dentista e Professor de Graduação e Pós Graduação do INAPÓS ( Pouso Alegre-MG).

${ }^{6}$ Farmacêutica Bioquímica, Mestre em Ciências - Patologia Geral, Doutoranda em Ciências - Patologia Clínica, Professora Substituta do Curso de Biomedicina da UFTM (Universidade Federal do Triangulo Mineiro).

${ }^{7}$ Farmacêutico Bioquímico, Professor Associado da UNIFAL-MG.
}

Autor correspondente: Jorge Kleber Chavasco- Universidade Federal de Alfenas, Rua Gabriel Monteiro da Silva 700 , Alfenas-MG- 37130-000, Telefone: 35-3299-1305. E-mail: jkchavasco@uol.com.br

\begin{abstract}
Resumo: A candidíase é uma infecção fúngica causada por leveduras do gênero Candida que vivem nas mucosas e só causam doença quando existem condições que favoreçam o seu crescimento, como nos pacientes imunodeprimidos infectados pelo vírus HIV. Os relatos de resistência verificados em isolados de Candida albicans, principalmente em pacientes imunocomprometidos, e a necessidade de um tratamento rápido e eficaz fazem com que haja um grande interesse em estudos que sejam capazes de utilizar testes de susceptibilidade "in vitro" para a escolha da terapia adequada. O objetivo deste trabalho foi de determinar a Concentração Inibitória Mínima (CIM) dos antifúngicos clotrimazol e terbinafina sobre 19 isolados de Candida albicans, oriundas de pacientes HIV positivos e HIV negativos com candidose oral eritematosa para detectar possível resistência. Utilizou-se a técnica de diluição de antifúngicos em agar e posterior inoculação das amostras em regiões demarcadas na placa de Petri. Verificou-se que a CIM para a terbinafina variou de 32 a $128 \mu \mathrm{g} / \mathrm{mL}$ enquanto que, para o clotrimazol, a CIM variou de 16 a $128 \mu \mathrm{g} / \mathrm{mL}$. Este estudo nos permitiu concluir que a maioria das cepas de $C$. albicans isoladas apresentou valores de CIM elevados indicando resistência e estes não variaram de um antifúngico para outro, bem como não houve diferenças das CIM entre as amostras de pacientes HIV positivos e HIV negativos.
\end{abstract}

Palavras-chave: candidiase bucal. terbinafina. clotrimazol.C. albicans . HIV

\section{Determination of Clotrimazole and Terbinafine Minimum Inhibitory Concentration on Candida albicans isolates from HIV-positive and HIV-negative patients oral mucosa}

\begin{abstract}
Candidiasis is a fungi infection caused by yeasts from Candida genus, that live in the mucosas and just causes illness when there are favoring conditions to its growth, like immune compromised HIV infected patients. Resistance reports verified in Candida albicans isolates, especially in those immune compromised, and fast and efficient treatment need cause there to be a great interest in studies capable of using in vitro susceptibility tests to adequate therapy choose. The objective of this study was to determine the Minimum Inhibitory Concentration (MIC) of antifungal agents clotrimazole and terbinafine on 19 isolates of Candida albicans isolated from HIV positive patients
\end{abstract}


and HIV-negative with oral erythematous candidiasis to detect possible resistance. Using agar antifungal dilution thecnic and sample at demarcated regions on Petri dish. It was verified that MIC to terbinafine varied from 32 to 128 $\mu \mathrm{g} / \mathrm{mL}$ while to clotrimazole, MIC varied from 16 to $128 \mu \mathrm{g} / \mathrm{mL}$. This study allowed concluding that almost samples showed elevated MIC values among HIV positive or negative patients.

Keywords: oral candidiasis. terbinafine. clotrimazole. C. albicans.HIV

\section{INTRODUÇÃO}

A candidíase ou candidose é uma infecção fúngica produzida pela levedura Candida albicans, que vive nas mucosas e causa doença quando existem condições que favoreçam o seu crescimento. É a mais comum das infecções fúngicas que afetam a boca; podem desenvolver-se em qualquer superfície da mucosa e em pacientes infectados pelo HIV, que normalmente, apresentam a lesão no palato duro e palato mole (AIDS, 2003).

No primeiro caso de doença notificado que, posteriormente, foi diagnosticado como AIDS, a candidíase foi descrita como uma das características da doença em 4 de cada 5 pacientes. É também encontrada nos aspectos clínicos de quase todos os pacientes que participam dos antigos grupos de risco: hemofílicos, pacientes que são submetidos a transfusões sanguíneas ou usuários de drogas. A forma bucal pode ser o primeiro sinal ou sintoma de infecção pelo HIV. Observam-se 3 formas clínicas predominantes em pessoas HIV positivo: Eritematosa, Pseudomembranosa e Queilite Angular (AIDS, 2003).
Geralmente, o tratamento é efetivo, pelo menos nos casos em que o paciente não se encontra nos estágios finais de infecção pelo HIV, sendo fundamental a identificação e eliminação do fator predisponente. $\mathrm{O}$ maior problema é que são infecções crônicas que requerem tratamentos contínuos. A terapêutica exige o uso de antifúngícos tópicos e sistêmicos e a incorporação de bochechos com substâncias alcalinas. A Nistatina aplicada topicamente, o Cetoconazol de uso sistêmico ou a Anfotericina B são medicamentos utilizados, bem como o Fluconazol, em casos de resistência. Uma boa higienização bucal é importante para o sucesso do tratamento .

Um dos primeiros medicamentos eficazes no tratamento de candidíase foi a nistatina. Esta droga, entretanto, apresenta toxicidade quando usada por via intravenosa e não é absorvida pelo trato gastrointestinal. Em função disso, novas pesquisas continuaram a ser feitas, propondo o uso de Anfotericina B, que apesar de alta eficácia é também dotada de alta toxicidade (MEDOFF, 1980; MEYER, 1994; WALSH, 1994). Outras drogas antifúngicas como a 5-fluorcitosina e derivados azólicos com reduzido efeito tóxico 
surgiram no mercado mais recentemente (TEREEL; HUGHES, 1992).

A candidíase de orofaringe, normalmente, diagnosticada em mais de $75 \%$ dos pacientes com AIDS, durante o decorrer da enfermidade, além de recidivar em alta freqüência leva a um desconforto durante a mastigação dos alimentos. Estes fatores acarretam diminuição do estado imunológico e faz-se necessário o tratamento eficaz e de maneira rápida. (KERRIDGE; NICHOLAS, 1986; IWATAK, 1992; DUPONT, 1994; COLOMBO, 1994). O uso freqüente de terapia antifúngica em pacientes com AIDS, visto as constantes recidivas de candidíase bucal ou esofágicas, é fator que provavelmente influencia na ocorrência de resistência a diferentes drogas .

O grande número de drogas antifúngicas, o relato de resistência verificado em isolados de Candida, principalmente em pacientes imunocomprometidos, e a necessidade de um tratamento rápido e eficaz fazem com que haja um grande interesse em estudos que sejam capazes de padronizar testes de susceptibilidade in vitro para a escolha da terapia adequada (MERZ, 1986; KORTING et al., 1988; SHADOMY; PFALLER, 1991; ALVES e CURY, 1992; GALGIANI et al., 1992; COLOMBO, 1994; NCCLS, 1997).

Os métodos utilizados na execução dos testes de suscetibilidade para fungos geralmente são adaptações daqueles empregados para bactérias. As técnicas disponíveis baseiam-se na diluição em caldo, diluição em ágar e difusão em ágar. Os dois primeiros testes, avaliam a concentração inibitória mínima (CIM) da droga capaz de inibir o crescimento do fungo, ou ainda a concentração fungicida mínima (CFM) que é a menor concentração da droga capaz de matar o fungo .

No entanto, os testes de sensibilidade a drogas in vitro, não têm sido empregados rotineiramente, embora eles forneçam informações valiosas quanto à pesquisa de novas substâncias, resistência aos antifúngicos de uso freqüente, controle terapêutico de infecções e caracterização de amostras fúngicas (MERZ, 1986; KORTING et al., 1988; SHAMADOMY; PFALLER, 1991).

Além disso, fatores como solubilidade, estabilidade química e modo de ação da droga, composição e pH dos meios de cultura, tempo e temperatura de inoculação, concentração do inóculo e a definição do ponto de inibição (McGINNIS, 1980; PFALLER et al. 1988; SHADOMMY; PFALLER, 1991; GALGIANI et al., 1992) são os principais interferentes na reprodutibilidade dos testes de sensibilidade aos antifúngicos, além da falta de utilização de um único método por diversos autores, para que seus resultados possam ser comparáveis (LACAZ; PORTO; MARTINS, 1991; GALGIANI et al., 1992). 
Dentre os antifúngicos utilizados, o Clotrimazol (Figura 1) apresenta amplo espectro de ação, inibindo a biossíntese do ergosterol e de outros esteróides, danificando e alterando a permeabilidade da membrana celular do fungo, resultando na perda de elementos intracelulares essenciais. Seu mecanismo de ação envolve também a inibição da biossíntese dos triglicérides e fosfolipídeos fúngicos, da atividade enzimática oxidativa e peroxidativa, resultando em aumento intracelular de concentrações tóxicas de peróxido de hidrogênio que contribuem para a deterioração de organelas subcelulares e necrose celular .

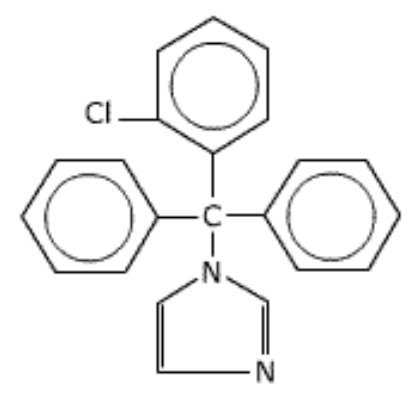

Figura 1 - Fórmula estrutural do Clotrimazol.

Já a Terbinafina (Figura 2) é um antifúngico sintético inibidor não competitivo da escalene epoxidase, enzima necessária para a biosíntese do ergosterol .

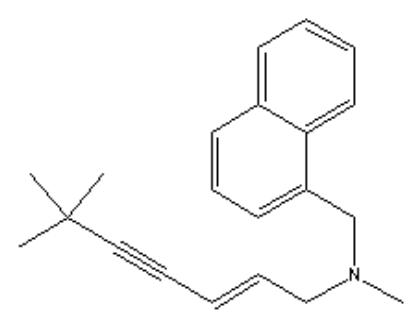

Figura 2 - Fórmula estrutural da Terbinafina.

Diante da necessidade de ampliação o conhecimento sobre a ação dos antifúngicos empregados na terapêutica da candidíase oral, o presente estudo teve como objetivo avaliar a eficiência dos antifúngicos Terbinafina e Clotrimazol em culturas isoladas de Candida albicans.

\section{MATERIAL E MÉTODOS}

Os isolados de C. albicans foram obtidos de 52 pacientes da clinica odontológica da Universidade de São Paulo (USP) com sintomas de candidíase bucal eritematosa, mediante assinatura de termo de consentimento livre e esclarecido. O presente trabalho foi submetido e aprovado pelo Comitê de Ética em Pesquisa da UNINCOR. Os antifúngicos utilizados nestes experimentos correspondem a produto de alta pureza fornecido pelos respectivos fabricantes. A técnica utilizada foi a da diluição em agar utilizada por ALVES e CURY (1992). A composição dos meios de cultura e soluções está descritas nos anexos.

Foi utilizado meio agar tampão fosfato. $\mathrm{O}$ agar foi fundido na água fervente e a seguir acrescentados os sais. O meio de cultura foi esterilizado em autoclave.

Como meios de reserva foram utilizados caldo e agar Yeast Nitrogen Base Phosphate (YNBP). Os componentes sólidos foram misturados em tampão levemente aquecido e 
posteriormente o meio foi esterilizado por filtração e conservado a $4^{\circ} \mathrm{C}$.

Os componentes foram misturados em condições assépticas e distribuídos em alíquotas de $7 \mathrm{~mL}$ em tubos estéreis e estocados a $4^{0} \mathrm{C}$ até o momento do uso.

O meio foi preparado no momento do uso. O meio de reserva foi misturado, sob condições assépticas, ao agar tampão fosfato fundido e resfriado a $45^{\circ} \mathrm{C}$. Foram distribuídos volumes de $18 \mathrm{~mL}$ em tubos estéreis e mantidos em banho - maria.

Ao tampão levemente aquecido foi adicionado tween 80 e volumes de $4 \mathrm{~mL}$ foram distribuídos em tubos, e a seguir esterilizados em autoclave a $121{ }^{\circ} \mathrm{C}$ por 15 minutos.

Para o preparo das soluções estoques de antifúngicos, foram pesados $25,6 \mathrm{mg}$ de cada antifúngico e dissolvidos em $1 \mathrm{~mL}$ de dimetil sulfóxido. Após o preparo da solução em tubo estéril, a mesma foi deixada em repouso por 10 minutos para auto esterilização e posteriormente realizado as diluições no caldo YNBP.

Para a diluição das drogas e dos meios, foi preparada uma série de 10 tubos, sendo que o primeiro tubo continha $19 \mathrm{~mL}$ de caldo YNBP e os demais, $7 \mathrm{~mL}$ de caldo YNBP. Ao primeiro tubo foi adicionado $1 \mathrm{~mL}$ da solução estoque do antifúngico e feita homogeneização. A partir deste tubo, foram realizadas diluições seriadas ao dobro, até alcançarmos o tubo numero 10. De cada tubo da série com as diluições da droga, foi transferido $2 \mathrm{~mL}$ para outros 10 tubos contendo cada um, $18 \mathrm{~mL}$ de agar YNBP mantidos a $45^{\circ} \mathrm{C}$.

Após homogeneização o meio com a droga incorporada foi vertido em placas de Petri estéreis. Após solidificação, estas foram conservadas em geladeira por no máximo uma semana. As concentrações finais das drogas variaram entre $0,25 \mu \mathrm{g} / \mathrm{mL}$ a 128 $\mu \mathrm{g} / \mathrm{mL}$.

Na obtenção dos inóculos, a partir dos cultivos de 48 horas a $25^{\circ} \mathrm{C}$ em agar Sabouraud dextrose das amostras de $C$. albicans, foram feitas suspensões em $5 \mathrm{~mL}$ de tampão fosfato com Tween 80 . O inóculo foi padronizado por fotometria em espectrofotômetro com absorbância entre 0,05 a 0,08 em $530 \quad \mathrm{~nm}$ equivalente a aproximadamente $10^{6} \mathrm{UFC} / \mathrm{mL}$ (PFALLER et al., 1988; SHADOMY e PFALLER, 1991; GALGIANI et al., 1992).

As suspensões padronizadas de $C$. albicans foram inoculadas num volume de $10 \mu \mathrm{L}$ nas placas contendo antifúngico num total de 20 amostras por placa. Após a secagem natural do inóculo as placas foram incubadas a $37^{\circ} \mathrm{C}$ por 24 horas. A leitura foi realizada anotando a presença ou ausência de crescimento da levedura e foi considerada a concentração inibitória mínima, a menor concentração da droga que impediu o crescimento. 


\section{RESULTADOS}

Das 52 amostras coletadas isolou-se 19 amostras de C. albicans As amostras de números 4 a 30 correspondem a pacientes HIV negativos e de 33 a 52 a pacientes HIV positivos. Verificou-se que a CIM para a terbinafina variou de 32 a $128 \mu \mathrm{g} / \mathrm{mL}$ e quanto ao clotrimazol a CIM variou de 16 a $128 \mu \mathrm{g} / \mathrm{mL}$. Os resultados encontram-se no quadro 1 e representam a media de três experimentos.

\section{DISCUSSÃO}

Infecções por Candida albicans só causam doença em condições que favoráveis e o seu desenvolvimento pode ocorrer em qualquer superfície mucosa. Neste trabalho foram realizados testes para a avaliação da CIM frente a amostras isoladas de Candida albicans. As amostras foram obtidas de pacientes HIV positivos e HIV negativos com candidíase bucal eritematosa.

A maioria das amostras apresentou CIM elevadas aos antifúngicos Terbinafina e Clotrimazol, ou seja, valores superiores 128 $\mu \mathrm{g} / \mathrm{mL}$. Considerando que os níveis plasmáticos da Terbinafina alcançam valores de $0,97 \mu \mathrm{g} / \mathrm{mL}$ com doses orais de $250 \mathrm{mg}$.

Tabela 01 - Determinação da concentração inibitória mínima de antifúngicos sobre amostras de $C$. albicans isoladas de pacientes HIV positivos e pacientes HIV negativos com candidíase eritematosa.

\begin{tabular}{c|c|c|c}
\hline \multirow{2}{*}{$\begin{array}{c}\text { Número da } \\
\text { Amostra }\end{array}$} & $\begin{array}{c}\text { Numero de } \\
\text { Referência } \\
\text { no ICB/USP }\end{array}$ & \multicolumn{2}{|c}{$\begin{array}{c}\text { Concentração Inibitória } \\
\text { Mínima (CIM) }(\mu \mathrm{g} / \mathrm{mL})\end{array}$} \\
\cline { 3 - 4 } & Terbinafina & Clotrimazol \\
\hline
\end{tabular}

\begin{tabular}{cccc}
\hline 4 & $13 \mathrm{P}$ & $>128,0$ & $>128,0$ \\
13 & $35 \mathrm{P}$ & 64,0 & $>128,0$ \\
16 & $22 \mathrm{P}$ & 32,0 & $>128,0$ \\
19 & $29 \mathrm{P}$ & $>128,0$ & $>128,0$ \\
21 & $17 \mathrm{P}$ & $>128,0$ & $>128,0$ \\
23 & $27 \mathrm{P}$ & $>128,0$ & 64,0 \\
24 & $34 \mathrm{P}$ & $>128,0$ & 64,0 \\
25 & $24 \mathrm{P}$ & $>128,0$ & 64,0 \\
27 & $25 \mathrm{P}$ & $>128,0$ & $>128,0$ \\
29 & $44 \mathrm{P}$ & $>128,0$ & $>128,0$ \\
30 & $11 \mathrm{P}$ & $>128,0$ & 64,0 \\
33 & $6 \mathrm{H}$ & $>128,0$ & $>128,0$ \\
37 & $26 \mathrm{H}$ & $>128,0$ & $>128,0$ \\
41 & $02 \mathrm{H}$ & $>128,0$ & $>128,0$ \\
42 & $21 \mathrm{LH}$ & $>128,0$ & $>128,0$ \\
46 & $9 \mathrm{H}$ & 64,0 & 16,0 \\
48 & $3 \mathrm{H}$ & $>128,0$ & $>128,0$ \\
51 & $25 \mathrm{H}$ & $>128,0$ & $>128,0$ \\
52 & $11 \mathrm{H}$ & $>128,0$ & $>128,0$ \\
\hline
\end{tabular}

podem-se classificar como resistente as amostras que apresentaram CIM superiores a este valor.

Quintero et al. (1986) comprovaram in vivo a eficácia do Clotrimazol em doses de $500 \mathrm{mg}$. Eles demonstraram que nesta concentração o Clotrimazol é tão eficaz quanto o Miconazol de $1200 \mathrm{mg}$.

Belkis Fernandes (1998) comparou a eficácia in vivo de Clotrimazol e Terbinafina em pacientes afetados com outra espécie de fungo, o Tinea pedis. Eles demonstraram que a terbinafina é capaz de produzir resposta eficaz mais rápida em período mais curto de tempo.

Marcano (1995) comparou a eficácia do Clotrimazol com Fluconazol a 150mg in vivo. A erradicação micótica foi verificada em 61,5 
$\%$ dos pacientes tratados com Clotrimazol e $64,0 \%$ dos pacientes tratados com Fluconazol.

Mena Cedilos et al., (1998) compararam a eficácia e a tolerância de Terbinafina (em creme) em candidíase das nádegas em lactantes. Os resultados demonstraram diferenças significativas e se considera a Terbinafina como alternativa em uma circunstância clinica.

Outro estudo comparativo foi realizado por Herrera et al. (1988, p.138-143). Eles compararam a eficácia nitrato de Butoconazol com o Clotrimazol. Os resultados demonstraram que a eficácia é muito similar em ambos os produtos na cura microbiológica, mas em testes clínicos e Terbinafina com valores de CIM muito mais baixos que o Clotrimazol. Mas quando estudados especialmente fungos leveduriformes, como a Candida albicans, a eficácia da Terbinafina é questionada tanto in vivo quanto in vitro (BELKYS FERNANDEZ, 1998).

\section{REFERÊNCIAS}

1. AIDS - Manifestações Orais. Infecções fúngicas. Disponível em:

$<$ http://www.odontogeral.hpg.ig.com.br/aids manifestbucais.html>. Acesso em: 19 maio 2003.

2. ALVES , S.H.; CURY, A. E. Sensibilidade de leveduras do gênero Candida isoladas de pacientes com câncer, à antifungicos poliênicos. Rev. Inst. Med. Trop., São Paulo, v.34, p. 251-254, 1992. terapêuticos o Butoconazol se mostrou mais eficiente.

Entre estudos sobre tratamento de vulvovaginite por Cândida, Itaia et al., (1985) compararam a eficiência do Clotrimazol e o Miconazol no tratamento desta doença. Eles selecionaram 80 pacientes e a porcentagem de pacientes curados com Clotrimazol foi de $80,0 \%$ no primeiro teste e $90,0 \%$ no segundo. Já o Miconazol apresentou 67,5\% e 77,5\% de eficácia, respectivamente.

De acordo com os dados do presente estudo, o Clotrimazol apresentou um resultado muito semelhante à Terbinafina contrariando alguns autores que citam a

\section{CONCLUSÃO}

Os resultados dos experimentos permitem concluir que os valores de CIM da Terbinafina e Clotrimazol foram muito semelhantes, com CIM maiores que 128 $\mu \mathrm{g} / \mathrm{mL}$ para a maioria das amostras. 
5. CURY, A . E.; MICHE, M.P. Atividade de derivados imidazólicos contra espécies de Candida isoladas de pacientes com câncer.

Rev. Microbiol., v.20, p.249-53, 1989.

6. CURY, A . E. ;MICHE, M. P. ; MINAMI, P.S., Leveduras isoladas de pacientes com câncer: incidência e sensibilidade à antibióticos. Rev Microbiol., v.20, p.102-7, 1989.

7. DUPONT, B. et al. Mycosis in AIDS patients. J. Med. Vet.Mycol., v.32, p.65-77, 1994.

8. GALGIANI, J.N. et al. Standartization of antifungal susceptibility testing. J.Med. Vet. Mycol. v.30, p.213-224,1992. Suppl.1.

9. HERRERA NAVA, Enrique. et al. Nitrato de butoconazole em candidiase vulvovaginal: estudo comparativo com clotrimazol.

Ginecol. Obstet. Mex, v.56 p.138-143, maio 1988.

10. ITAIA, J. H.et al. Estudo comparativo com clotrimazol e miconazol e em tratamento local de candidiase vulvovaginal. Obstet. Ginecol Latinoam, v.43, n.3/4, p.108-112, mar./abr. 1985.

11. IWATA,K. Drug resistence in human pathogenic fungi. Eur. J. Epidemiol., v.8, p.407-421, 1992.

12. KERRIDGE, D.; NICHOLAS, R. O. Drug resistence in the opportunist pathogens Candida albicans and Candida glabrata.. J. Antimicrob. Chemother. , v.18, p.39-49, 1986. Suppl.B.

13. KORTING, H.C.et al. "In vitro" susceptibilities and biotypes of Candida albicans isolates from oral cavities of patients infected with human immunodeficiency virus. J. Clin. Microbiol.,v.26, p.2626-2631, 1988. 14. LACAZ, C.S.; PORTO, E.; MARTINS, J. E. C. Micologia médica. 8.ed. São Paulo: Sarvier, 1991. P.695.

15. MARCANO, Carmen et al. Eficácia e segurança de fluconazol a doses de $150 \mathrm{mg}$.
Comparadas com clotrimazol no tratamento de pacientes com tinea crusis e pedis. Arch. Venez. Farmacol. Ter. v.14, n.1, p.35-38, 1995.

16. McGINNIS, M.R. Laboratory handbook of medical mycology. New York: Academic Press, 1980. p.661.

17. MEDOFF, G.; KOBAYASHI, G.A. The polyenes . In: Speller,D. (Ed.) Atifungal chemotherapy. New York: John Willey, 1980. p.3-33.

18. MENA CEDILOS, Carlos Alfrido. Estudo comparativo entre terbinafina em creme contra detoconazol em creme, eficácia e tolerância no tratamento de candidiase na zona del panal em lactantes. Bol. Méd. Hosp. Infant. Méx., v.55, n.10, p.563-568, out. 1998.

19. MERZ, W.G. Susceptibility testing of medically important fungi. Adv. Exp. Med. Biol. v.202, p.127-134, 1986.

20. MEYER, R.D. Treatment of fungal infections in patients with HIV-infection or AIDS. Zbl.Bakt, v.281, p.1-7, 1994.

21. NCCLS ( National Cmmitee for Clinical Loboratory Standards) Reference method for broth dilution antifungal suscepytibility testing fou yeast: approved standard. Document v.17-A , p.1-29,1997.

22. PFALLER, M.A. et al. Multicenter evaluation of four methods of yeast inoculum preparation. J.Clin. Microbiol. , v.26, p.1437-1441, 1988.

\section{QUINTERO, CARLOS; SEINAUI,} JORGE. Comparação da eficácia e tolerância de clotrimazol. Rev. Colomb. Obstet.

Ginecol., v.37, n.5, p.376-384, 1986. 24. SHADOMY, S.; PFALLER , M.A . Laboratory studies with antifungal agents:susceptibility tests quantitation in body fluids and bioassays. In : Manual of clinical microbiology. 5. ed. Washington: Americam Society for Microbiology, 1991, p.1173-1183. 
25. TERREL, C.L.; HUGHES, C.E.

Antifungal agents used for deep- seated

mycotic infections. Mayo Clin.Proc., v.67, p.69-91, 1992.

26. WALSH, T. J. et al. Recent advances in epidemiology, prevention and treatment of invasive fungal infections in neutropenic patients. J. Med. Vet. Mycol., v.32, p.33-51, 1994. 